\title{
XIII CONGRESO INTERNACIONAL DE TEORÍA DE LA EDUCACIÓN
}

Entre el 26 y el 28 de noviembre de 2014, se celebró en la Facultad de Ciencias de la Educación de la Universidad de Sevilla el XIII Congreso Internacional de Teoría de la Educación, en esta ocasión convocado bajo el lema Educación Superior: El reto de la empleabilidad. Con la asistencia de 150 personas y la representación de más de cincuenta universidades en el evento, el XIII CITE se desarrolló a través de tres conferencias plenarias ("Competencias profesionales y empleabilidad", a cargo de la Dr. ${ }^{a}$ Paula Kyrö, de Finlandia; "Estrategias de acción para la mejora de la empleabi-

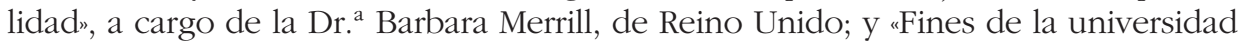


y empleabilidad", a cargo del Dr. Miguel Ángel Santos Rego, de la Universidad de Santiago de Compostela), dos mesas de expertos ("Pedagogía de la empleabilidad" e "Inserción profesional y empleabilidad") y cinco sesiones de comunicaciones ("Currículum y competencias para la empleabilidad", "Cultura emprendedora, inserción profesional y empleabilidad", "Fines de la educación superior", "Ética profesional y empleabilidad" y "Desarrollo humano, globalización y empleabilidad").

El inequívoco interés que genera el debate sobre la empleabilidad en estos momentos en el panorama internacional se ha visto fortalecido por un plan de difusión de gran impacto de los resultados de investigación debatidos en el Congreso. Los trabajos presentados al Congreso se han publicado en soporte online en la revista Procedia-Social and Behavioral Sciences, n. ${ }^{\circ} 139$ (Ed. Elsevier), publicada en ScienceDirect. Más de setenta trabajos aportan una riqueza indudable al debate sobre los desafíos que la empleabilidad presenta a la educación superior actual. Con diferentes perspectivas, desde planteamientos diversos ideológica y culturalmente, podemos encontrar contribuciones inequívocas a dichos desafíos focalizadas en diversos tópicos: el desarrollo humano sostenible, la globalización, el ámbito de las competencias formativas, los fines de la educación, la ética profesional, la cultura emprendedora y el emprendimiento, la inserción profesional, el currículum, y algunos aspectos culturales y cuestiones vinculadas a la equidad, así como a las políticas aplicadas. Este conjunto de trabajos contribuye resueltamente a avivar el debate sobre el reto de la empleabilidad en nuestras sociedades actuales y nos reclama la renovación permanente de nuestras responsabilidades y compromisos con la construcción de un mundo más humanizado y mejor.

Sintetizando las principales aportaciones del XIII CITE, tal vez podríamos cifrar las siguientes:

1. Generación de un amplio debate sobre el desafío de la empleabilidad en el marco de las instituciones superiores de educación. Este diálogo se ha dinamizado vigorosamente por la participación de alta calidad que han proporcionado los congresistas, profesores universitarios de más de cincuenta universidades españolas y extranjeras.

2. Análisis de los vínculos entre formación, inserción profesional y empleabilidad. La parcelación de los debates en mesas y sesiones especializadas ha permitido el desarrollo pormenorizado de una buena cantidad de elementos ligados a la tríada mencionada.

3. Profundización en los modelos institucionales que requiere su impulso. Se ha planteado en los debates la necesidad de establecer pertinentes alianzas institucionales como vía tal vez más adecuada en estos momentos para el impulso de la empleabilidad.

4. Discusión sobre las politicas de empleabilidad. Se ha dado curso en este foro a discusiones sobre el factor político como un eje fundamental en el desarrollo de la empleabilidad. En este sentido, se ha debatido sobre la pertinencia de las últimas directrices políticas nacionales e internacionales. 
5. Análisis de las complejas relaciones entre empleabilidad y cultura. Ha habido un gran número de aportaciones en esta dirección, mostrándose la considerable diversidad y notoria pluralidad factorial que alberga el binomio cultura y empleabilidad.

6. Estudio de los vínculos entre empleabilidad y promoción de una cultura emprendedora. Buena parte de las discusiones han girado sobre la empleabilidad y su proyección en la promoción del emprendimiento en las instituciones sociales y, especialmente, educativas.

7. Reflexión y consenso sobre la empleabilidad y su formación como ejes de cambio en la educación superior. Podríamos decir que este foro ha concluido que no es posible considerar hoy la educación superior sin una atención prioritaria a la empleabilidad y su desarrollo, aunque esta atención no cubra el arco de lo que podríamos entender por misión universitaria o propia de una institución educativa de este nivel.

Sin renunciar a la crítica, constitutiva del saber y distintiva de la universidad, en el seno del XIII Congreso Interuniversitario de Teoría de la Educación se ha generado un amplio, abierto y vivo debate sobre el desafío que la empleabilidad supone para las instituciones superiores. Desde la convicción de que hoy difícilmente la educación superior puede seguir siendo un espacio abierto a posibilidades para el crecimiento personal, para el cambio social y para la profundización de la democracia, si no acometemos en profundidad, con el sosiego que merece y también con la energía que reclama, el sentido y alcance de la empleabilidad en las instituciones superiores de enseñanza propias del siglo XXI. 